\title{
Investing in a Shared Supplier in a Competitive Market: Stochastic Capacity Case
}

\author{
Anyan Qi \\ Naveen Jindal School of Management, The University of Texas at Dallas, Richardson, Texas 75080, USA, axq140430@utdallas.edu
}

\author{
Hyun-Soo Ahn, Amitabh Sinha \\ Stephen M. Ross School of Business, University of Michigan, Ann Arbor, Michigan 48109, USA, hsahn@umich.edu, amitabh@umich.edu
}

\begin{abstract}
Wh firms invest in a shared supplier, one key concern is whether the invested capacity will be used for a competitor. In practice, this concern is addressed by restricting the use of the capacity. We consider what happens when two competing firms invest in a shared supplier. We consider two scenarios that differ in how capacity is used: exclusive capacity and first-priority capacity. We model firms' investment and production decisions, and analyze the equilibrium outcomes in terms of the number of investing firms and capacity levels for each scenario; realized capacity is a stochastic function of investment levels. We also identify conditions under which the spillover effect occurs, where one firm taps into the other firm's invested capacity. Although the spillover supposedly intensifies competition, it actually discourages firms' investment. We also characterize the firms' and supplier's preference about the capacity type. While the non-investing firm always prefers spillovers from the first-priority capacity, the investing firm does not always want to shut off the other firm's access to its leftover capacity, especially when allowing spillover induces the other firm not to invest. The supplier's preference depends on the trade-off between over-investment and flexibility.
\end{abstract}

Key words: capacity investment; supplier development; Cournot competition; non-cooperative game History: Received: April 2013; Accepted: December 2014 by Albert Ha, after 3 revisions.

\section{Introduction}

In many supply chains, multiple firms source from the same set of suppliers. Such supply chain structures benefit from achieving economies of scale and obtaining reliable and high-quality supply, but there are also risks such as the firms being exposed to shortage of supplies or greater vulnerability to supply disruptions. In order to mitigate the risks, many firms invest in shared suppliers, even if the firms compete against each other.

For example, firms may invest in the supplier to expand the supplier's capacity, avoid the supplier's bankruptcy, or improve the quality of products. A major cosmetic brand directly invested in its South Korean supplier, Cosmax, which also served many other cosmetic companies. Intel invested in ASMI by purchasing $4 \%$ of its common shares to foster material development (LaPedus 2009), even though ASMI is a supplier to AMD. Of course, firms invest in suppliers not just for capacity expansion; for instance, GM provided \$210 million to AAM in 2009 to keep it out of bankruptcy (Haywood 2009), and Walmart sent experts to help Chinese suppliers improve sustainability while the suppliers also supply to other retailers (Aston 2009). In the literature, these investments can be considered as a part of "supplier development" (Handfield et al. 2000).
When a firm invests in a shared supplier, there is a natural competitive threat: the competitors may take advantage of the firm's investment, which would intensify the competition and therefore reduce the investing firm's profits. To avoid this, the investing firm may impose contractual constraints on the supplier that dictate exactly how the increased capabilities can be used. In this study, we specifically focus on the contractual relationships governing firms' investments in the supplier's capacity and their consequences.

One example that illustrates the framing of our model is Foxconn's recent investment in Sharp. In 2012, Foxconn (Hon Hai Precision Industry Co.) invested $\$ 1.6$ billion in Sharp: the investment included a $46.5 \%$ stake in a single LCD factory in Sakai, Japan, and an agreement to buy $50 \%$ of the panels produced from the factory (Dignan 2012). In this case, Foxconn claimed exclusive use of the $50 \%$ capacity, while Sharp was free to use the remaining 50\% for others, including Sharp's own products in the tablet and TV markets.

Another motivation to invest in a shared supplier is to prevent other firms from receiving preferential treatment. When a significant portion of the supplier's capacity could be first tapped by the investing firm, the non-investing firm is at disadvantage in meeting the demand. This concern partly explains why Samsung also invested in Sharp shortly after 
Foxconn's investment. It was reported that Samsung invested \$110 million in Sharp to "prevent its competitor, particularly Hon Hai and Apple, from gaining too much control," and "secure a steady supply of LCD panels" (Osawa and Lee 2013).

In this study, we consider a supply network where two firms compete in the market while sharing a supplier, and examine how the different contractual forms affect the firms' investment decisions and resulting profits for the two firms and the supplier. When a supplier serves competing firms, evaluating the benefit of investment is not trivial. Investment provides a buyer increased access to the supplier's capacity, but such investment is costly and may benefit the competing firm if it also has more access to the capacity (a spillover effect). To prevent unintended spillover, buyers often restrict the use of the invested resources so that a buyer has enough capacity to satisfy its demand. Therefore, for both supplier and buyer, the economics of investment becomes more complex with presence of competing firms. In this study, we develop a model that captures the investment decisions of competing firms, and study the consequences of the contractual restriction that governs the capacity use.

We examine two common restrictions used in practice: Exclusive (the investing firm gets exclusive access to the invested capacity), and First-Priority (one firm can access the unused portion of the other firm's invested capacity, if any). We characterize equilibrium outcomes in terms of the number of investing firms and capacity levels. We show that, fewer firms invest as the fixed investment cost increases, and within a regime where the number of investing firms remains the same, the capacity level decreases in the variable capacity cost. We identify when and to what extent the spillover effect occurs. The spillover occurs only when the fixed cost is intermediate under the first-priority capacity. We also show that the variable cost affects how much capacity the investing firm will build and consequently how much capacity the competing firm may tap into. We next examine the impact of the spillover effect on the supply chain performance by comparing the exclusive and first-priority capacity. We observe that the spillover can curb competition between the firms and discourage investment. In equilibrium, the first-priority capacity is lower than the exclusive capacity, and so is the number of investing firms. On the other hand, the spillover effect may help both firms by reducing the chance of the firms being trapped in a prisoner's dilemma.

Given the observation about the equilibrium capacity levels, we further examine which type of capacity that the buying firms and the supplier prefer. We find the buying firms' preference depends on two effects: the leading effect when the firm becomes the only investor and has advantages in accessing capacity, and the spillover effect when the non-investing firm taps into the invested capacity. In contrast to naive intuition, we show that the investing firm does sometimes prefer the first-priority capacity. This is because restricting the capacity can trigger the other firm also to invest and intensify the competition. The non-investing firm, however, always prefers the firstpriority capacity as it can access more capacity. The supplier's preference is driven by the trade-off between the over-investment in the exclusive capacity, and the flexibility in utilizing the first-priority capacity. Building on this, we discuss which type of capacity will be chosen in the supply chain under two scenarios. When the supplier can dictate the capacity type, the exclusive capacity is likely to emerge as the ultimate choice. On the other hand, when the investing firm determines the capacity type, the first-priority capacity may also emerge as the ultimate choice.

\subsection{Literature Review}

Our work falls within the literature of supplier development, which refers to a buyer's efforts to identify, measure, and improve supplier performance (Handfield et al. 2000, Krause et al. 1998). Many papers in this area have studied different ways to improve supply chain efficiency by buying firms' investment in cost reduction (Iyer et al. 2005), quality (Zhu et al. 2007), capacity (Li 2013, Li and Debo 2009), reliability (Wang et al. 2010), and financial subsidy (Babich 2010). In all these papers, there is a single buyer; none of the above papers consider the case of competing firms investing in a shared supplier.

Two papers study firms investing in a shared supplier to improve the reliability. Wadecki et al. (2012) show that, when firms compete, they are less likely to invest in a shared supplier. Wang et al. (2014) consider the knowledge spillover associated with investing in a shared supplier, and show spillover often improves the firms' profits. Both papers consider a binary yield model thus there is no competition for the supplier's capacity. In contrast, the supplier's limited capacity, and its allocation to each firm under the two capacity types, are key features of our model.

Our paper is also related with the capacity management literature. A number of papers including (Plambeck and Taylor 2005, Ülkü , et al. 2005, 2007, Van Mieghem 2003) survey and deal with various issues in managing supplier's capacity. In this stream, two papers are related to our work. Li et al. (2011) consider how capacity reservation options and access fee affect the supplier's profit. Qi et al. (2013) examine how the market environment and demand correlation affect a firm's decision in sharing unused capacity of a supplier. This paper differs from the two papers in two aspects. First, our model considers a market where firms compete against each other. Thus, a 
central question is how competition affects investment decision. Second, in contrast to the two papers, our model features stochastic capacity due to uncertain yields or technology.

\section{Model}

We consider a supply chain with a supplier (denoted by $s$ ), and two competing firms $(i=1,2)$. The supplier produces a new product (or component), and sell it at a wholesale price $c$ to both firms. Thus, in the absence of capacity investment, both firms are ex ante symmetric. The two firms compete a la Cournot in the market with the inverse demand function: $P\left(q_{1}, q_{2}\right)=a-b\left(q_{1}+q_{2}\right)$, where $a$ is the total market size, and $b$ the price sensitivity parameter.

The supplier needs to build capacity to fulfill orders. Prima facie, the supplier incurs the investment cost for the capacity. At this stage, buying firms have opportunities to invest in the supplier's capacity. In return for the investment, the firms are endowed with a portion of capacity, for which the firms can impose restrictions on how the capacity is used. Details of these restrictions will determine the amount of capacity that firms can use at their discretion, and the output produced for each firm. To capture this, we consider a two-stage model. In the first stage, firms decide whether to invest in the supplier, and if so, by how much. In the second stage, the firms set order quantities and compete. We assume that the capacity investment cost includes both a fixed cost, $w_{0}$, and a variable cost, $w$. Here, the fixed cost may represent the cost associated with commissioning and starting up a new facility, and the variable cost may represent the cost of tools or new workers which is proportional to the size of the investment.

We assume that firms do not know exactly the yield of capacity at the time of investment. This assumption reflects the fact that many factors besides capital investment (e.g., physical capacity, available technology, process yield, and staffing plan) influence the realized capacity at the time of production. This assumption is consistent with the literature on unreliable suppliers (e.g., Wadecki et al. 2012, Wang et al. 2014) and is appropriate for modeling capacity in high-tech industries, agriculture, and vaccine production.

Specifically, the supplier's total capacity is $K_{s}=\left(k_{0}+k_{1}+k_{2}\right) \xi$, where $k_{0}$ represents the supplier's base capacity, $k_{i}(i=1,2)$ is the capacity level invested by firm $i$, and $\xi$ is a random variable with support $[0,1]$ reflecting the yield between the realized capacity and the theoretical maximum capacity projected at the time of investment. It follows that the supplier's total capacity stochastically increases as the buying firms' investment increases. The fact that all the three parts of the supplier's capacity, $k_{0} \xi, k_{1} \xi$, and $k_{2} \xi$ are positively correlated, reflects that these capacities are built for the same product at the supplier's site, which are subject to the same risk of random yield.

In return for the investment, firms can restrict how the endowed capacity should be used. While there are different restrictions used in practice, a widely used choice is making capacity "exclusive": a firm exclusively uses the invested capacity, and disallows any other use even if there is leftover. Another widely used form is that the investing firm demands to fulfill its own order first ("first priority"), but the supplier is free to use any leftover.

If neither firm invests in the supplier, then both firms are identical from the perspective of the supplier. In this case, no priority will be given to either firm. If the sum of order quantities is less than the supplier's capacity, allocation is trivial. When the total quantity is greater than the supplier's capacity, we use the uniform allocation rule used in Cachon and Lariviere (1999) and Sprumont (1991). Under the uniform allocation, if one firm orders more than the other firm, it will receive the minimum of its own order quantity and the capacity left from serving the other firm. Unlike other allocation rules that can induce order inflation, the uniform allocation rule is known to be truth-inducing, and nonmanipulable; Both firms order their preferred quantities within the limits of an upper bound that enforces the capacity constraint. We assume that the uniform allocation rule is common knowledge in our game. Since we assume that the two buying firms are ex ante identical, if neither firm invests, the supplier is effectively allocating one-half of the capacity to each firm in equilibrium; if the firms' order quantities exceed capacity, they will each get one-half following the uniform allocation rule. Thus, if neither firm invests, we use $\xi$ to represent the realization of $\xi$, and then firm $i$ 's capacity level is $\frac{k_{0}}{2} \xi$.

Under the exclusive contract, if firm $i(i=1,2)$ does not fully use the initial endowed capacity of $\left(\frac{k_{0}}{2}+k_{i}\right) \xi$, any remaining capacity will be wasted. On the other hand, under the first-priority contract, the investing firms demand to fulfill their orders first, but the supplier is free to use any leftover to fulfill other orders. That is, firm $i$ can order up to $\left(\frac{k_{0}}{2}+k_{i}\right) \xi$ plus any leftover from the other firm's invested capacity $\left(\frac{k_{0}}{2}+k_{j}\right) \xi$, $i \neq j$. That means if the firm with larger capacity has some leftover, the firm with smaller capacity is able to use the leftover part. Likewise, if the firm with smaller capacity has some leftover, the firm with larger capacity is also able to use the leftover.

To further illustrate the first-priority capacity, suppose firm $i$ invests in a higher capacity level than firm $j$ : $k_{i} \geq k_{j}$. As firms compete on the same Cournot market, it can be shown that, in any equilibrium, if firm $j$ does not utilize all of its invested capacity, then firm $i$ will also have leftover capacity. However, even when firm $j$ exhausts its invested capacity, firm $i$ may still have some 
leftover that firm $j$ may use in equilibrium. Thus, in equilibrium, the only firm who will use the leftover capacity is the firm with smaller capacity. Consequently, under the first-priority capacity, firm $i$ can order up to $\left(\frac{k_{0}}{2}+k_{i}\right) \xi$, while firm $j$ can order up to its capacity $\left(\frac{k_{0}}{2}+k_{j}\right) \xi$ plus any leftover capacity from firm $i$.

The remaining sequence of events is as follows. After the capacity has been realized, firms place their orders (with quantities specified by $q_{1}$ and $q_{2}$ ) subject to the above capacity constraints and compete in the downstream market. Therefore, firm $i$ 's second-stage profit is given as $q_{i} P\left(q_{1}, q_{2}\right)-c q_{i}$. Likewise, the supplier's second-stage revenue is simply $c\left(q_{1}+q_{2}\right)$.

The total profit of each firm is the expected secondstage profit, minus investment cost, if any. We assume that the buyer's investment is entirely used to build capacity, so the supplier's overall profit is the expected value of $c\left(q_{1}+q_{2}\right)$. Note that relaxing this assumption does not change our results. For ease of exposition, we assume that neither the firms nor the supplier incurs any other costs, although incurring additional unit production costs at both firms will not change the analytical findings. We assume that firms and supplier are profit-maximizing, risk-neutral agents, and all game parameters are common knowledge.

Remark on sequence of events. In our model, we frame the sequence of events as firms first invest in the supplier. Then the capacity is realized, and firms place orders and serve the market. However, an alternative framework to interpret the sequence of events is that firms invest in and order from the supplier before the capacity uncertainty is resolved. Then, after the capacity is realized, firms adjust production decisions. In Appendix S4, we show that this alternative sequence does not change our results and insights.

\section{Exclusive Capacity Contract}

We first analyze the exclusive capacity case, that is, the invested capacity cannot be accessed by the other firm. To determine an equilibrium, we solve the game by backward induction. Therefore, we present the analysis for the second-stage quantity game for given realized capacity, and then solve the first-stage investment game.

\subsection{Second-Stage Quantity Game}

Following section 2 , let $\left(k_{1}, k_{2}\right)$ denote the capacity investment of the two firms. Given the realized supplier capacity $k_{s}=\left(k_{0}+k_{1}+k_{2}\right) \xi$ and investment decisions in the first stage, firms set quantities $\left(q_{1}, q_{2}\right)$ subject to constraints. At $\left(q_{1}, q_{2}\right)$, the market clearing price, $P\left(q_{1}, q_{2}\right)$, is given by $P\left(q_{1}, q_{2}\right)=a-b\left(q_{1}+q_{2}\right)$. The equilibrium production quantities are determined by solving the following:

$$
\begin{aligned}
& \pi_{1}^{e}\left(k_{1}, k_{2}, \xi\right)=\max _{\left.q_{1} \leq \frac{k_{0}}{2}+k_{1}\right) \xi} q_{1} P\left(q_{1}, q_{2}\right)-c q_{1}, \quad \text { and } \\
& \pi_{2}^{e}\left(k_{1}, k_{2}, \xi\right)=\max _{q_{2} \leq\left(\frac{k_{0}}{2}+k_{2}\right) \xi} q_{2} P\left(q_{1}, q_{2}\right)-c q_{2} .
\end{aligned}
$$

The equilibrium order quantities and resultant profits when $k_{1} \geq k_{2}$ are presented in Lemma 1 . The results are symmetric for case $k_{1}<k_{2}$, thus omitted. For ease of exposition, throughout the paper, we use $m_{0}\left(k_{1}, k_{2}\right)$ to represent the unit margin if neither firm is constrained by the invested capacity $\left(k_{1}, k_{2}\right)$ when ordering optimally. Likewise, under a subgame perfect equilibrium $m_{1}\left(k_{1}, k_{2}\right)$ represents the unit margin if only one firm is constrained by the invested capacity $\left(k_{1}, k_{2}\right)$. As we assume $k_{1} \geq k_{2}$ and firms compete in the Cournot market, if only one firm is constrained, that firm can only be firm 2. Similarly, we use $m_{2}\left(k_{1}, k_{2}\right)$ to represent the unit margin if both firms are constrained. For simplicity, we suppress the dependency of $m_{i}\left(k_{1}, k_{2}, \xi\right)$ on $\left(k_{1}, k_{2}, \xi\right)$ when there is no confusion. All proofs are relegated to the appendix. We define $m_{i}\left(k_{1}, k_{2}, \xi\right)$ as follows, where $k_{s}=\left(k_{0}+k_{1}+k_{2}\right) \xi$.

$$
\begin{aligned}
& m_{0}\left(k_{1}, k_{2}, \xi\right)=\frac{a-c}{3} ; \\
& m_{1}\left(k_{1}, k_{2}, \xi\right)=\frac{a-b\left(\frac{k_{0}}{2}+k_{2}\right) \xi-c}{2} ; \\
& m_{2}\left(k_{1}, k_{2}, \xi\right)=a-b k_{s}-c .
\end{aligned}
$$

LEMMA 1 (FIRMS' EQUILIBRIUM ORDER QUANTITY AND EX POST PROFIT). Let the capacity investment sizes be $\left(k_{1}, k_{2}\right)$. The resulting subgame yields the following:

$$
\begin{array}{lll}
\hline \text { Realized yield } \xi & \text { Order quantity }\left(q_{1}^{*}, q_{2}^{*}\right) & \text { ex post profit }\left(\pi_{1}^{e}, \pi_{2}^{e}\right) \\
\hline 0 \leq \xi \leq \frac{a-c}{b\left(\frac{3 k_{0}}{2}+2 k_{1}+k_{2}\right)} & \left(\left(\frac{k_{0}}{2}+k_{1}\right) \xi,\left(\frac{k_{0}}{2}+k_{2}\right) \xi\right) & \left(m_{2}\left(\frac{k_{0}}{2}+k_{1}\right) \xi, m_{2}\left(\frac{k_{0}}{2}+k_{2}\right) \xi\right) \\
\frac{a-c}{b\left(\frac{3 k_{0}}{2}+2 k_{1}+k_{2}\right)}<\xi \leq \frac{a-c}{3 b\left(\frac{k_{0}}{2}+k_{2}\right)} & \left(\frac{a-c-b\left(\frac{k_{0}}{2}+k_{2}\right) \xi}{2 b},\left(\frac{k_{0}}{2}+k_{2}\right) \xi\right) & \left(\frac{m_{1}\left[a-c-b\left(\frac{k_{0}}{2}+k_{2}\right) \xi\right]}{2 b}, m_{1}\left(\frac{k_{0}}{2}+k_{2}\right) \xi\right) \\
\frac{a-c}{3 b\left(\frac{k_{0}}{2}+k_{2}\right)} \leq \xi \leq 1 & \left(\frac{a-c}{3 b}, \frac{a-c}{3 b}\right) & \left(\frac{m_{0}(a-c)}{3 b}, \frac{m_{0}(a-c)}{3 b}\right)
\end{array}
$$


We note that the lemma illustrates the case where $\frac{a-c}{3 b\left(\frac{k_{0}}{2}+k_{2}\right)} \leq 1$. For the cases where $\frac{a-c}{3 b\left(\frac{k_{0}}{2}+k_{2}\right)}>1$, the analysis is exactly the same except that one or two regions in the table are empty. We discuss these cases in Appendix S1.

\subsection{First-Stage Investment Game}

Building on Lemma 1, we now analyze the firms' investment decisions in the first stage. In this stage, the firm needs to make capacity investment decisions: whether to invest in the supplier, and if so, by how much. In preparation, we first define firms' expected profit, given firms' capacity investment $\left(k_{1}, k_{2}\right)$. We define an indicator $\mathbf{1}_{C}: \mathbf{1}_{C}=1$ if condition $C$ is met and 0 otherwise. Let $V_{i}^{e}\left(k_{1}, k_{2}\right)$ be the firm i's expected profit when the capacity investment sizes of the two firms are $\left(k_{1}, k_{2}\right)$ and the two firms follow a subgame perfect strategy in the quantity game. Applying the results from Lemma 1 , we write $V_{i}^{e}\left(k_{1}, k_{2}\right)$ when $k_{1} \geq k_{2}$ as follows. The expressions when $k_{1}<k_{2}$ are symmetric.

$$
\begin{aligned}
& V_{1}^{e}\left(k_{1}, k_{2}\right)=E\left[\pi_{1}^{e}\left(k_{1}, k_{2}, \boldsymbol{\xi}\right)\right]-w_{0} \mathbf{1}_{\left\{k_{1}>0\right\}} \\
& -w k_{1}=\int_{0}^{\frac{3\left(\frac{a-c}{2}+2 k_{1}+k_{2}\right)}{2}} m_{2}\left(\frac{k_{0}}{2}+k_{1}\right) \xi f(\xi) d \xi \\
& +\int_{\frac{a-c}{3 b\left(\frac{k_{0}}{2}+k_{2}\right)}}^{1} \frac{m_{0}(a-c)}{3 b} f(\xi) d \xi \\
& +\int_{\frac{3 b-c}{b\left(\frac{k-c}{2}+2 k_{1}+k_{2}\right)}}^{\frac{a-c}{\left.3+\frac{k}{2}+k_{2}\right)}} \frac{m_{1}\left[a-c-b\left(\frac{k_{0}}{2}+k_{2}\right) \xi\right]}{2 b} f(\xi) d \xi \\
& -w_{0} \mathbf{1}_{\left\{k_{1}>0\right\}}-w k_{1} \\
& V_{2}^{e}\left(k_{1}, k_{2}\right)=\int_{0}^{\frac{a-c\left(\frac{a-c}{2}+2 k_{1}+k_{2}\right)}{2}} m_{2}\left(\frac{k_{0}}{2}+k_{2}\right) \xi f(\xi) d \xi \\
& +\int_{\frac{a-c}{\left.3 b \frac{k_{0}}{2}+k_{2}\right)}}^{1} \frac{m_{0}(a-c)}{3 b} f(\xi) d \xi \\
& +\int_{\frac{a-c}{b\left(\frac{a k_{0}}{2}+2 k_{1}+k_{2}\right)}}^{\frac{a-c}{3 b\left(\frac{k_{0}}{2}+k_{2}\right)}} m_{1}\left(\frac{k_{0}}{2}+k_{2}\right) \xi f(\xi) d \xi \\
& -w_{0} \mathbf{1}_{\left\{k_{2}>0\right\}}-w k_{2}
\end{aligned}
$$

For both firms, the expected profit is the sum of three terms, minus investment costs. The first term represents the profit when the yield is low and the capacity is binding, so both firms use up all the available capacity. The second term represents the profit when the yield is sufficiently large and neither firm is bounded by its capacity constraint. The third term represents the case where firm 2 is capacity-constrained, while firm 1 with more invested capacity is not. With the induced profit functions, we derive the equilibrium capacity investment as follows.

There are three possible equilibrium regimes: neither firm invests, one firm invests, or both firms invest. In each regime, the investing firm(s) also decides how much to invest in the supplier. If neither firm investing and both firms investing are both equilibria, we use the equilibrium that the firms remain at the status quo and do not invest in the supplier. This equilibrium is focal for two reasons. First, at the beginning of the game, neither firm has invested in the supplier. Thus, neither firm investing is a natural choice for a focal point. Second, it also preserves the continuity of decisions as the regions where both equilibria exist are adjacent to the region where neither firm investing is the only equilibrium. We next identify the conditions under which each specific equilibrium arises and show how the equilibrium evolves from one to another with respect to the fixed investment cost, $w_{0}$, and the variable investment cost, $w$.

Proposition 1 (FIrm's equILIBRIUM EXClusive CAPACITY INVESTMENT). There exist two equilibrium switching curves, $\underline{w}_{0}^{e}(w)$ and $\bar{w}_{0}^{e}(w)$, such that $\underline{w}_{0}^{e}(w) \leq \bar{w}_{0}^{e}(w)$, and

i) When the fixed cost is small $\left(w_{0} \leq \underline{w}_{0}^{e}(w)\right)$, both firms invest $k^{e}$ in the supplier. The equilibrium capacity, $k^{e}$ decreases in $w$ and follows

$$
k^{f} \triangleq\left\{\begin{array}{c}
k: \int_{0}^{\frac{a-c}{3 b} \frac{\left.k_{0}+k\right)}{2}}\left[a-c-3 b\left(\frac{k_{0}}{2}+k\right) \xi\right] \\
\xi f(\xi) d \xi-w=0
\end{array}\right\} .
$$

Furthermore, there exists a function $w_{0}^{e}(w)$ such that the equilibrium leads to a prisoner's dilemma in the region for all $w \in\left[w_{0}^{e}(w), \underline{w}_{0}^{e}(w)\right]$. Under the prisoner's dilemma we have $V_{i}^{e}\left(k^{e}, k^{e}\right) \leq V_{i}^{e}(0,0)$ for $i=1,2$.

ii) When the fixed cost is intermediate $\left(\underline{w}_{0}^{e}(w)<w_{0} \leq \bar{w}_{0}^{e}(w)\right)$, only one firm invests in the supplier, where the equilibrium capacity, $k_{1}^{e}$, decreases in $w$ and follows

$$
\begin{array}{r}
k_{1}^{e} \triangleq\left\{k: \int_{0}^{\frac{a-c}{b\left(\frac{3 k_{0}}{2}+2 k\right)}}\left[a-c-b\left(\frac{3 k_{0}}{2}+2 k\right) \xi\right]\right. \\
\xi f(\xi) d \xi-w=0\} .
\end{array}
$$

iii) When the fixed cost is high $\left(w_{0}>\bar{w}_{0}^{e}(w)\right)$, neither firm invests.

Furthermore, $\underline{w}_{0}^{e}(w)$ and $\bar{w}_{0}^{e}(w)$ decrease in the variable cost w.

The equilibrium can be seen in Figure 1. For a given variable cost $w$, we observe that the number 
Figure 1 Equilibrium Investment Outcomes with Exclusive Capacity

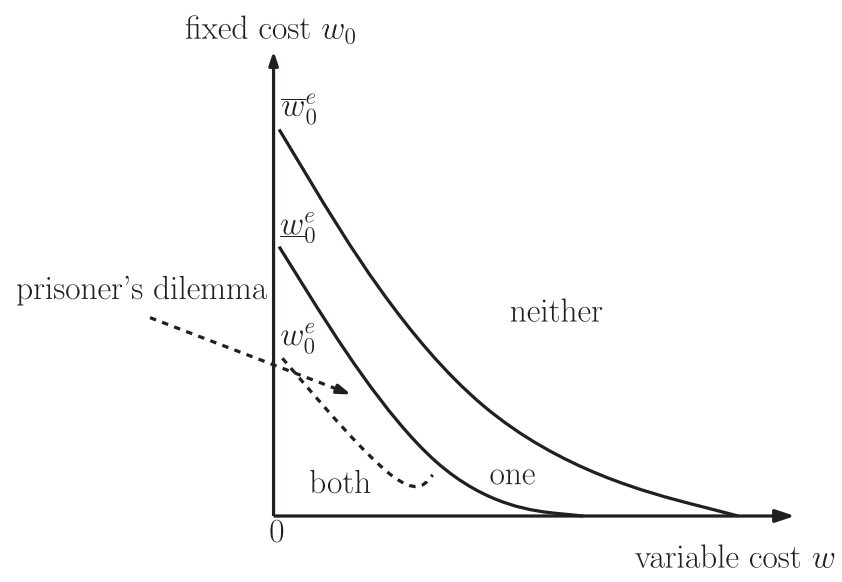

"neither": neither firm invests. "one": one firm invests. "both": both firms invest.

of investing firms decreases as the fixed cost $w_{0}$ increases. When the fixed investment cost is fairly low, that is, $w_{0} \leq w_{0}^{e}(w)$, both firms invest in the supplier's capacity. The level of invested capacity, however, is determined by the variable cost $w$, as shown in Equation (3). When the fixed investment cost is close to the threshold $\underline{w}_{0}^{e}(w)$, as both firms find it dominant to invest, both firms can be trapped in a prisoner's dilemma, where both firms earn a lower profit than what they would have earned if neither firm had invested. While overinvestment in capacity also occurs when $w_{0} \leq w_{0}^{e}(w)$, in this case, the fixed investment cost is not big enough relative to the firms' profit, thus the firms are not trapped in a prisoner's dilemma. Therefore, the prisoner's dilemma equilibrium arises as a combination of both over-investment in capacity and the non-negligible fixed investment cost. When the fixed capacity cost is moderate, that is, $\underline{w}_{0}^{e}(w)<w_{0} \leq \bar{w}_{0}^{e}(w)$, an asymmetric equilibrium where only one firm invests is sustained. In this regime, the investing firm gains enough profit being the capacity leader, while the non-investing firm finds it not necessary to invest because the gain from investment is limited and not enough to cover the costs. When the fixed capacity cost is very high, that is, $\bar{w}_{0}^{e}(w)<w_{0}$, neither firm invests, and each firm will rely on the supplier's base capacity.

For a given fixed cost $w_{0}$, we also observe that fewer firm invests as the variable capacity cost $w$ increases. When both firms invest, an increase in $w$ has both a direct and an indirect impact on the firms' profits. As $w$ increases, the firms are less incentivized to invest in the capacity ( $k^{e}$ decreases in $w$, ) and as a result, this negatively affects the buying firm's capacity and profit. On the other hand, as $w$ increases, the capacity of both firms decreases. This increases the market price and positively affects the firm's profit. Therefore, whether an increase in the variable cost will increase or decrease the firm's profit will depend on the relative magnitude of the two effects, and this is why we observe the non-monotonicity in the prisoner's dilemma region (see the dashed line in Figure 1).

When only one firm invests, a higher variable cost decreases investment level and the investing firm's profit. Therefore, if the investing firm's profit is less than the profit with no firm investing at a given $w$, then the same equilibrium holds when $w$ is even higher: This is why the switching curve $\bar{w}_{0}^{e}(w)$ decreases in $w$. With exclusive capacity, however, a decrease in the investing firm's capacity lowers quantity and raises the market price. Therefore, the noninvesting firm's profit increases in $w$. We observe that as $w$ increases, this increase in the non-investing firm's profit when only one firm invests outweighs the possibility to increase the firms' profit when both firms invest. Thus, we observe the monotonicity in the equilibrium switching curve $\underline{w}_{0}^{e}(w)$.

\section{First-Priority Capacity Contract}

Under this contract, the invested capacity will be used first for the investing firm, and any leftover can be used to fulfill other orders. The sequence of events is the same as before. In any equilibrium, we observe that only the firm with smaller capacity may tap into the leftover capacity. To see why, suppose one firm (say firm 1) invests in more capacity than the other firm. Since the firms engage in Cournot competition, it can be shown that if firm 2 has any leftover, then firm 1 has leftover in equilibrium. On the other hand, the converse is not necessarily true. Consequently, in any equilibrium, only the firm with smaller capacity can access the leftover, that is, firm 2 can now order up to $k_{s}-q_{1}$ instead of $\left(\frac{k_{0}}{2}+k_{2}\right) \xi$. When firm 2 invests in more capacity than firm 1, the analysis is symmetric, thus omitted. The equilibrium outcome of the following quantity game is shown in Lemma 2.

$$
\begin{aligned}
& \pi_{1}^{f}\left(k_{1}, k_{2}, \xi\right)=\max _{q_{1} \leq\left(\frac{k_{0}}{2}\right) \xi} q_{1} P\left(q_{1}, q_{2}\right)-c q_{1}, \quad \text { and } \\
& \pi_{2}^{f}\left(k_{1}, k_{2}, \xi\right)=\max _{q_{2} \leq\left(k_{s}-q_{1}\right)} q_{2} P\left(q_{1}, q_{2}\right)-c q_{2} .
\end{aligned}
$$

LEMMA 2 (FIRMS' EQUILIBRIUM ORDER QUANTITY AND EX POST PROFIT). Let the capacity investment sizes be $\left(k_{1}, k_{2}\right)$, and the resulting subgame yields the following: 


\begin{tabular}{lll}
\hline Realized yield $\xi$ & Order quantity $\left(q_{1}^{*}, q_{2}^{*}\right)$ & ex post profit $\left(\pi_{1}^{e}, \pi_{2}^{e}\right)$ \\
\hline $0 \leq \xi \leq \frac{a-c}{b\left(\frac{3 k_{0}}{2}+2 k_{1}+k_{2}\right)}$ & $\left(\left(\frac{k_{0}}{2}+k_{1}\right) \xi,\left(\frac{k_{0}}{2}+k_{2}\right) \xi\right)$ & $\left(m_{2}\left(\frac{k_{0}}{2}+k_{1}\right) \xi, m_{2}\left(\frac{k_{0}}{2}+k_{2}\right) \xi\right)$ \\
$\frac{a-c}{b\left(\frac{3 k_{0}}{2}+2 k_{1}+k_{2}\right)}<\xi \leq \frac{2(a-c)}{3 b\left(k_{0}+k_{1}+k_{2}\right)}$ & $\left(\frac{a-c}{b}-k_{s}, 2 k_{s}-\frac{a-c}{b}\right)$ & $\left(m_{2}\left(\frac{a-c}{b}-k_{s}\right), m_{2}\left(2 k_{s}-\frac{a-c}{b}\right)\right)$ \\
$\frac{2(a-c)}{3 b\left(k_{0}+k_{1}+k_{2}\right)} \leq \xi \leq 1$ & $\left(\frac{a-c}{3 b}, \frac{a-c}{3 b}\right)$ & $\left(\frac{m_{0}(a-c)}{3 b}, \frac{m_{0}(a-c)}{3 b}\right)$ \\
\hline
\end{tabular}

Under any realization of $\xi$, only one of the two outcomes arises: either the entire capacity is exhausted, or there is still leftover capacity and neither firm is constrained by its capacity. There does not exist a situation where only one firm has exhausted its capacity, while the other firm still has leftover. This result is not surprising when $\xi$ is very low (so the capacity is really tight) or $\xi$ is very high (so the capacity is sufficiently large), but even when the realized capacity is moderate, $\frac{a-c}{b\left(\frac{3 k_{0}}{2}+2 k_{1}+k_{2}\right)}<\xi \leq$ $\frac{2(a-c)}{3 b\left(k_{0}+k_{1}+k_{2}\right)}$, a situation where only one firm's invested capacity is used up does not occur. Intuitively, the firm with less capacity has incentive to use leftover because the benefit from satisfying more demand beyond its own invested capacity dominates the negative impact of the lower market price. On the other hand, because firms engage in the Cournot competition, if the non-investing firm does not want to access the leftover capacity, the investing firm will also find it not profitable to use the leftover to produce more. Thus, when the capacity type is first-priority, either the entire capacity is exhausted, or neither firm is constrained by capacity. The following result presents the investment outcome for the first-priority capacity.

PROPOSITION 2 (FIRMS' EQUILIBRIUM FIRST-PRIORITY CAPACITY INVESTMENT). There exist two equilibrium switching curves, $\underline{w}_{0}^{f}(w)$ and $\bar{w}_{0}^{f}(w)$, such that $\underline{w}_{0}^{f}(w) \leq \bar{w}_{0}^{f}(w)$ and

i) When the fixed cost $w_{0}$ is low $\left(w_{0} \leq \underline{w}_{0}^{f}(w)\right)$, both firms invest in the supplier, where the equilibrium capacity, $k^{f}$, decreases in $w$ and is given by

$$
k^{f} \triangleq\left\{\begin{array}{l}
k: \int_{0}^{\frac{a-c}{3 b\left(\frac{k}{2}+k\right)}}\left[a-c-3 b\left(\frac{k_{0}}{2}+k\right) \xi\right] \\
\xi f(\xi) d \xi-w=0
\end{array}\right\} .
$$

Furthermore, there exists a function $w_{0}^{f}(w)$ such that a prisoner's dilemma arises between $w_{0}^{f}(w)$ and $\underline{w}_{0}^{f}(w): V_{i}^{f}\left(k^{f}, k^{f}\right) \leq V_{i}^{f}(0,0)$ for $i=1,2$.

ii) When the fixed cost $w_{0}$ is intermediate $\left(\underline{w}_{0}^{f}(w)<w_{0} \leq \bar{w}_{0}^{f}(w)\right)$, the spillover effect occurs and only one firm invests in the supplier, where the equilibrium capacity, $k_{1}^{f}$, decreases in $w$ and is given by

$$
k_{1}^{f} \triangleq\left\{\begin{array}{c}
\int_{0}^{\frac{a-c}{b\left(\frac{3 k_{0}}{2}+2 k\right)}}\left[a-c-b\left(\frac{3 k_{0}}{2}+2 k\right) \xi\right] \xi f(\xi) d \xi \\
k: \quad+\int_{\frac{a-c}{b\left(\frac{a-c}{2}+2 k\right)}}^{\frac{2(a-c)}{3 b\left(k_{0}+k\right)}}-2\left[a-c-b\left(k_{0}+k\right) \xi\right] \\
\xi f(\xi) d \xi-w=0
\end{array}\right\} .
$$

iii) When the fixed cost $w_{0}$ is high $\left(w_{0}>\bar{w}_{0}^{f}(w)\right)$, neither firm invests.

Furthermore, $\bar{w}_{0}^{f}(w)$ decreases in $w$.

The structure of the equilibrium is similar to Proposition 1: as $w_{0}$ increases, the equilibrium shifts from two firms investing, to one firm investing, and finally to no firm investing. We also observe that the switching curve $\bar{w}_{0}^{f}(w)$ decreases in $w$. However, with firstpriority capacity, we observe that the spillover where the non-investing firm uses the leftover occurs in an equilibrium where one firm invests. To understand why the spillover does not occur under the other two regions, we first note that firms are able to access the same capacity level in both cases, as the firms make the same level of investment in equilibrium in a Cournot market. Consequently, both firms exhaust all the available capacity or both have leftover. Furthermore, the firm's investment decision is affected by the spillover. This is reflected by the second term in condition (6): $\quad \int_{\frac{2(a-c)}{3\left(k_{0}+k\right)}}^{\frac{3\left(\frac{k}{2}+c k\right)}{2}+2 k}-2\left[a-c-b\left(k_{0}+k\right) \xi\right] \xi f(\xi) d \xi$. In this case, the realized capacity is moderately high, and the benefit from the investment that allows the firm to access more capacity, is dominated by the loss due to the decreasing market price (this happens because the non-investing firm accesses the leftover and intensifies competition). Thus, the investing firm is more likely to build a smaller capacity.

Finally, we notice the switching curve $\underline{w}_{0}^{f}(w)$ is not necessarily monotone in $w$ due to the spillover effect. 
The investing firm's profit decreases in the variable cost $w$ and therefore the equilibrium switching curve $\bar{w}_{0}^{e}(w)$ that defines the one firm investing regime decreases in $w$. However, the non-investing firm's profit does not necessarily increase with respect to $w$ (we observe that the profit of the non-investing firm increases in $w$ in the exclusive capacity case.) While a higher $w$ leads to a lower invested capacity and raises the price in the Cournot market, the non-investing firm may access the investing firm's leftover capacity. Thus, when the investing firm lowers the capacity level, it could decrease the non-investing firm's available capacity and resultant profit. Therefore, the noninvesting firm's profit may increase or decrease in the variable capacity $\operatorname{cost} w$, depending on which effect is stronger. Thus, we observe the equilibrium switching curve $\underline{w}_{0}^{e}(w)$ is not necessarily monotone in the variable cost $w$ as shown in Figure 2.

\section{Spillover Effect: Comparing Exclusive and First-Priority Capacity}

In sections 3 and 4 , we identified three equilibrium regimes-neither firm investing, one firm investing, and both firms investing, as well as how the equilibrium and its capacity level change in the capacity cost. We learned that the main difference between the two capacity types is that the first-priority capacity leads to a spillover equilibrium. In this section, we are interested in how the spillover effect affects the equilibrium outcomes, and as a result, the buying firms' and supplier's preference about the capacity type.

\subsection{Impact on the Equilibrium Outcomes}

At first glance, it seems that the spillover effect will always intensify competition because it gives both firms greater flexibility to access the supplier's capacity. However, our analysis shows that, in spite of this

Figure 2 Equilibrium Investment Outcomes with First-Priority Capacity

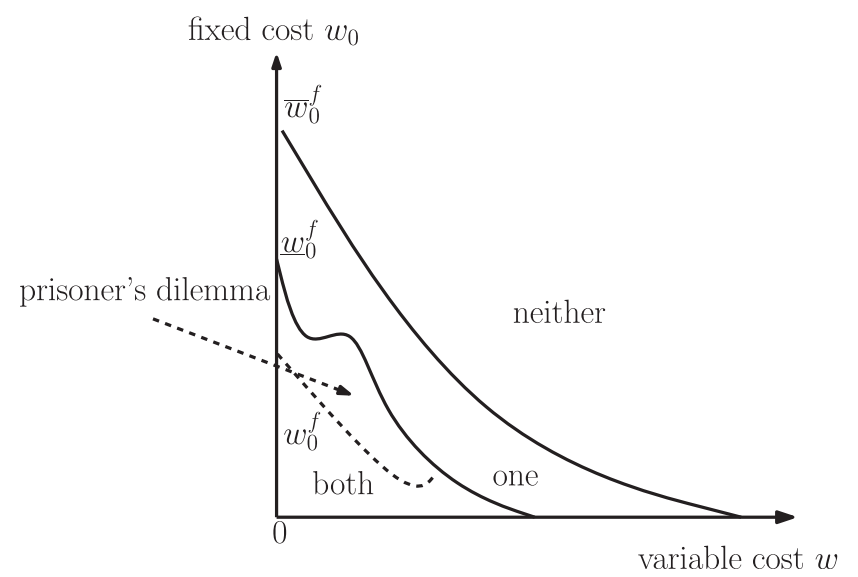

"neither": neither firm invests. "one": one firm invests. "both": both firms invest. added flexibility, the spillover effect indeed discourages firms from investing in their supplier. Therefore, it can decrease both the number of investing firms and the capacity levels. As firms invest less aggressively, the spillover mitigates the risk of both firms being trapped in a prisoner's dilemma. Our next proposition formally summarizes these impacts.

PROPOSITION 3 (IMPACt OF SPILLOVER EFFECT ON THE EQUILIBRIUM OUTCOMES).

i) The number of investing firms is higher with exclusive capacity than with first-priority capacity, that is, $\underline{w}_{0}^{f}(w) \leq \underline{w}_{0}^{e}(w)$ and $\bar{w}_{0}^{f}(w) \leq \bar{w}_{0}^{e}(w)$.

ii) The total capacity is larger with exclusive capacity than with first-priority capacity.

iii) The prisoner's dilemma region is larger with exclusive capacity than with first-priority capacity, that is, $\left[w_{0}^{f}(w), \underline{w}_{0}^{f}(w)\right] \subseteq\left[w_{0}^{e}(w), \underline{w}_{0}^{e}(w)\right]$ for all $w$.

With the first-priority capacity, it looks as if competition is intensified with firms' access to each other's leftover. This is true if the supplier's total capacity level remains the same for both contracts: more units are produced and the market clearing price is lower with the first-priority capacity. However, the result shows, because firms can access the other firm's leftover capacity and do not need as much invested capacity as before, firms are less motivated to invest. Therefore, firms invest less under the first-priority capacity and the spillover effect indeed curbs competition in two ways. First, by Proposition 3(i), the number of investing firms is lower with the first-priority capacity than with the exclusive capacity. Thus, in a region where both firms invest with exclusive capacity, it is possible that only one firm invests with firstpriority capacity. Similarly, in a region where one firm invests with exclusive capacity, neither firm may invest with first-priority capacity. Second, in Proposition 3(ii), we observe that when only one firm invests, the invested capacity level is lower with first-priority capacity, and when there are more firms investing with exclusive capacity, the invested capacity level is also lower with first-priority capacity, indicating that the spillover effect decreases the total capacity.

Proposition 3(iii) shows the prisoner's dilemma region is smaller with the first-priority capacity. With first-priority capacity, the non-investing firm is less incentivized to invest aggressively as it can access the leftover. As a result, over-investment is less likely to occur and so is the prisoner's dilemma.

\subsection{Capacity Type Preference of Buying Firms and the Supplier}

We next analyze the implication of the spillover effect on the firms' and supplier's profit and their preference of the capacity types. In particular, we further 


\section{Figure 3 Two Equilibrium Paths to Illustrate Buying Firms' Preference about the Capacity Types}

(a) One-firm-investing regions do not overlap (when $\left.\underline{w}_{0}^{e}(w) \geq \bar{w}_{0}^{f}(w)\right)$

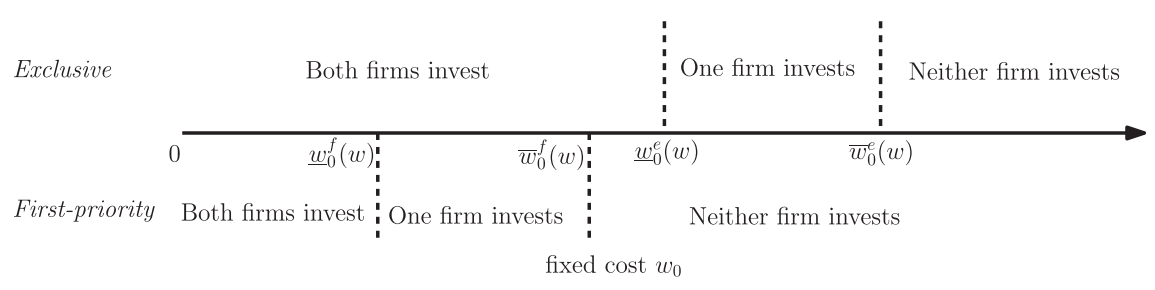

(b) One-firm-investing region overlaps $\left(\right.$ when $\left.\underline{w}_{0}^{e}(w)<\bar{w}_{0}^{f}(w)\right)$

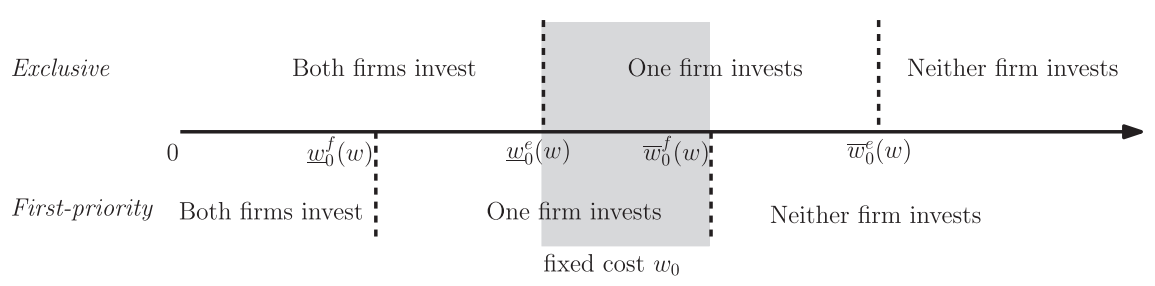

The light-gray area in (b) indicates the overlapping one-firm-investing region.

investigate which capacity type the buying firms and supplier would prefer.

Buying firms' preference. The preference of buying firms is driven by two main effects: the leading effect associated with being the only investor, and the spillover effect that occurs with the first-priority capacity. When only one firm invests, the advantage of accessing more capacity allows this firm to extract more profit from the market than the non-investing firm. On the other hand, with the spillover effect the non-investing firm is able to access the leftover capacity invested by the other firm. Consequently, the buying firm's preference depends on which of the two effects is stronger.

Comparing the equilibrium outcomes under exclusive and first-priority capacity in Propositions 1 and 2, two cases arise: the one-firm-investing region does not overlap, that is, $\underline{w}_{0}^{e}(w) \geq \bar{w}_{0}^{f}(w)$ as shown in Figure $3 a$, or the one-firm-investing region overlaps, that is, $\underline{w}_{0}^{e}(w)<\bar{w}_{0}^{f}(w)$ as shown in Figure $3 \mathrm{~b}$. We first illustrate the results for the non-overlapping case in the proposition below, and then extend the analysis to the overlapping case. We note that when the onefirm-investing regions do not overlap, the analysis for firms' preference is symmetric and it does not matter which firm becomes the investing firm when only one firm invests. Therefore, without loss of generality, we assume the investing firm is firm 1 when only one firm invests in this case.

PROPOSITION 4 (BUYING FIRMS' CAPACITY TYPE PREFERENCE WHEN $\left.\underline{w}_{0}^{e}(w) \geq \bar{w}_{0}^{f}(w)\right)$.

i) When $0 \leq w_{0}<\underline{w}_{0}^{f}(w)$, the firms are indifferent between the exclusive and first-priority capacity, as both firms invest the same amount in both settings.

ii) When $\underline{w}_{0}^{f}(w) \leq w_{0}<\bar{w}_{0}^{f}(w)$, both firms prefer first-priority capacity (with only one firm investing) over exclusive capacity (where both firms would invest).

iii) When $\bar{w}_{0}^{f}(w) \leq w_{0}<\underline{w}_{0}^{e}(w)$, both firms prefer first-priority capacity (with neither firm investing) over exclusive capacity (where both firms would invest).

iv) When $\underline{w}_{0}^{e}(w) \leq w_{0}<\bar{w}_{0}^{e}(w)$, firm 1 prefers the exclusive capacity while firm 2 prefers the first-priority capacity.

v) When $w_{0} \geq \bar{w}_{0}^{e}(w)$, the firms are indifferent between the exclusive and first-priority capacity, as neither firm invests.

The results are presented in Figure 4a. Proposition 4(i) shows that if both firms invest, that is, $0 \leq w_{0}<\underline{w}_{0}^{f}(w)$, the firms are indifferent between the two capacity types. To understand this, we notice that both firms compete in the Cournot market and both firms invest in the same capacity level. Therefore, both firms will either exhaust all the available capacity or have some capacity leftover. This makes the first-priority capacity de facto exclusive. Similarly, when neither firm invests, that is, $w_{0} \geq \bar{w}_{0}^{e}(w)$ as shown in Proposition 4 (v), both firms will be able to access the same capacity level, and therefore the firstpriority capacity is also de facto exclusive. In these two cases, the firms are indifferent about capacity types.

In other cases, one may expect that the investing firm should always prefer the exclusive capacity and disallow the other firm from accessing its leftover. However, our analysis indicates that this is not 
Figure 4 The Buying Firms' Preference about the Capacity Types

(a) One-firm-investing regions do not overlap (when $\underline{w}_{0}^{e}(w) \geq \bar{w}_{0}^{f}(w)$ )

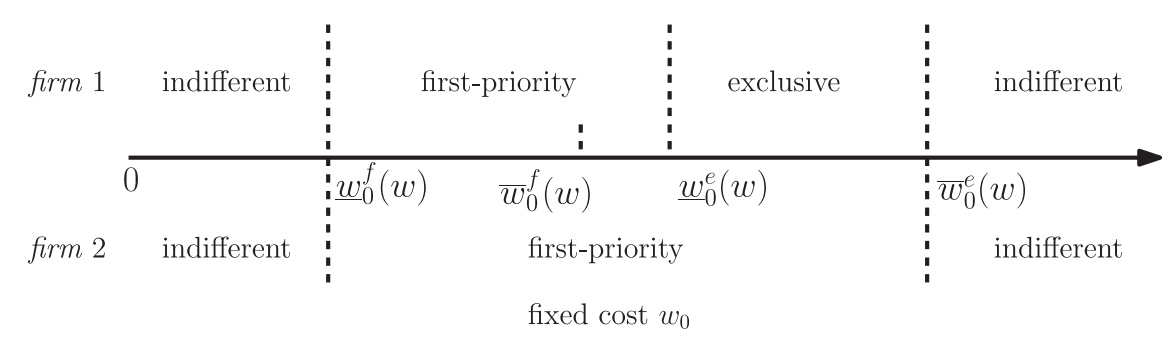

(b) One-firm-investing region overlaps (when $\underline{w}_{0}^{e}(w)<\bar{w}_{0}^{f}(w)$ )

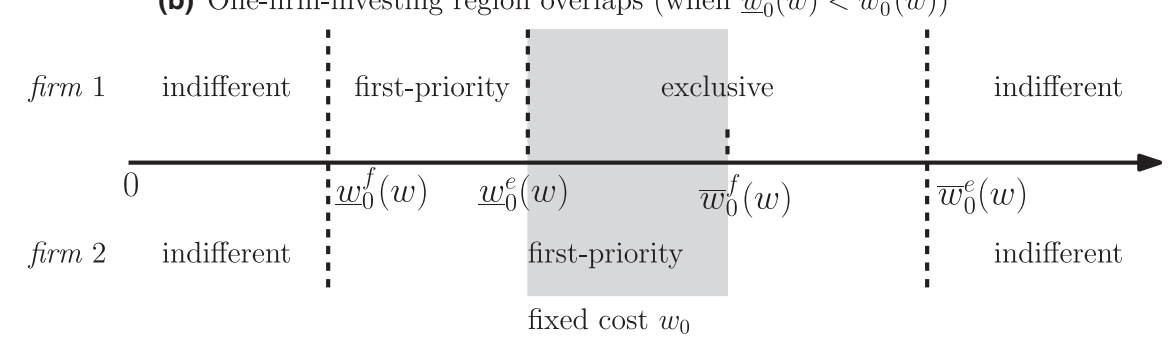

In the overlapped one-firm-investing region in (b) (the light-gray region $\underline{w}_{0}^{e}(w) \leq w_{0}<\bar{w}_{0}^{f}(w)$ ): only one firm invests under either capacity type, so there are two cases: firm 1 invests under both capacity types, or firm 1 invests under the exclusive capacity and firm 2 invests under the first-priority capacity.

always the case. In the range $\underline{w}_{0}^{f}(w) \leq w_{0}<\bar{w}_{0}^{f}(w)$, the exclusive capacity will trigger firm 2 to invest and firm 1 will lose the benefit from the leading effect under the first-priority capacity. Therefore, firm 1 prefers to grant its competitor access to its invested capacity as shown in Proposition 4(ii). In this case, firm 2 also prefers the first-priority capacity in the hope of being able to free-ride on the investing firm's leftover.

Finally, in the middle range, $\bar{w}_{0}^{f}(w) \leq w_{0}<\underline{w}_{0}^{e}(w)$, both firms prefer the first-priority capacity (where no firm invests) to the exclusive capacity (where both firms invest). This is a direct consequence of the spillover effect: the spillover prevents firms from overinvestment and being trapped in the prisoner's dilemma.

We next consider the case with overlapped onefirm-investing regions as shown in Figure 3b. As the fixed cost $w_{0}$ increases, there are also five regions to analyze. Except for the overlapped one-firm investing region, that is, $\underline{w}_{0}^{e}(w) \leq w_{0}<\bar{w}_{0}^{f}(w)$, the equilibrium outcomes in the other four regions are the same as in the non-overlapping case (subcase i, ii, iv, and v). Therefore, we focus on the overlapped one-firminvesting region, $\underline{w}_{0}^{e}(w) \leq w_{0}<\bar{w}_{0}^{f}(w)$.

When $\underline{w}_{0}^{e}(w) \leq w_{0}<\bar{w}_{0}^{f}(w)$, only one firm invests in equilibrium regardless of the capacity type. In this range, two distinct cases arise as $w_{0}$ changes. In the first case, the firm which invests under the exclusive capacity, also invests when the capacity type is firstpriority, and without loss of generality, we label the investing firm as firm 1 . In the second case, the firm which invests when the capacity type is exclusive is different from the firm which invests when the capacity type is first-priority. Without loss of generality, we label the investing firm under the exclusive capacity as firm 1 and the investing firm under the first-priority capacity as firm 2 . We summarize the firms' preference in the corollary below.

Corollary 1 (Buying Firms' CAPACITY TYPE PREFERENCE WHEN $\left.\quad \underline{w}_{0}^{e}(w)<\bar{w}_{0}^{f}(w)\right)$. When $\underline{w}_{0}^{e}(w) \leq w_{0}<\bar{w}_{0}^{f}(w)$, firm 1 prefers the exclusive capacity and firm 2 prefers the first-priority capacity.

The firms' capacity type preference is shown in Figure $4 \mathrm{~b}$. When the same firm (firm 1) invests in equilibrium under both capacity types, the investing firm gains more when the capacity is exclusive than when the capacity is first-priority. Therefore, the investing firm (firm 1) prefers exclusive capacity. On the other hand, the non-investing firm (firm 2) prefers firstpriority capacity for the benefit of free-riding on the investing firm's leftover.

When the investing firm is different under both capacity types, the investing firm under exclusive capacity (firm 1) gains more under the exclusive capacity than it does as the non-investing firm under the first-priority capacity. Therefore, firm 1 prefers the exclusive capacity. On the other hand, the investing firm under the first-priority capacity (firm 2) gains more under the first-priority capacity. This is 
because firm 2 enjoys benefit of the leading effect under the first-priority capacity, while it suffers for not being able to access the other firm's leftover as the non-investing firm under the exclusive capacity. Thus, firm 2, the investing firm under the first-priority capacity, prefers the first-priority capacity over the exclusive capacity. In other words, firm 2 would like to grant its competitor access to its invested capacity. We next discuss the supplier's preference about the capacity types.

Supplier's preference. The supplier's expected profit with the exclusive and first-priority capacity, $V_{s}^{e}$ and $V_{s}^{f}$, when firms invest in $\left(k_{1}, k_{2}\right)$ and $k_{1} \geq k_{2}$ are as follows. The expressions are symmetric when $k_{1}<k_{2}$. Recall that the supplier's realized capacity is denoted by $k_{s}=\left(k_{0}+k_{1}+k_{2}\right) \xi$, and $c$ is the unit profit.

$$
\begin{aligned}
V_{s}^{e}\left(k_{1}, k_{2}\right)= & \int_{0}^{\frac{3\left(\frac{a-c}{2}+2 k_{1}+k_{2}\right)}{3}} c k_{s} f(\xi) d \xi \\
& +\int_{\frac{a-c}{b\left(\frac{3 k_{0}}{2}+2 k_{1}+k_{2}\right)}}^{\frac{a-c}{\left.k_{0}+k_{2}\right)}} c\left[\frac{a-c}{2 b}+\left(\frac{k_{0}}{2}+k_{2}\right) \frac{\xi}{2}\right] f(\xi) d \xi \\
& +\int_{\frac{a-c}{3 b\left(\frac{k}{2}+k_{2}\right)}}^{1} \frac{2 c(a-c)}{3 b} f(\xi) d \xi
\end{aligned}
$$

$$
\begin{aligned}
V_{s}^{f}\left(k_{1}, k_{2}\right)= & \int_{0}^{\frac{2(a-c)}{3 b\left(k_{0}+k_{1}+k_{2}\right)}} c k_{s} f(\xi) d \xi \\
& +\int_{\frac{2(a-c)}{3 b\left(k_{0}+k_{1}+k_{2}\right)}}^{1} \frac{2 c(a-c)}{3 b} f(\xi) d \xi
\end{aligned}
$$

Comparing the supplier's profits under the two contacts leads to a few interesting observations. From the supplier's perspective, the spillover is a two- edged sword. While the spillover effect improves the capacity utilization of the supplier, it also reduces the supplier's total capacity as shown in Proposition 3. Therefore, it is not obvious how the supplier should prefer the exclusive capacity vs. the first-priority capacity.

However, we show that if the fixed investment cost is low, both firms invest and the supplier is indifferent about capacity types since both types induce the same amount of investment in the supplier. If the fixed cost is high, the supplier is also indifferent between the capacity types since neither firm invests in the supplier anyway. In between, if more firms invest with exclusive capacity, the supplier benefits from the over-investment with exclusive capacity more than the flexibility with first-priority capacity. Similar to the discussions on buying firms' preference, we first illustrate the results for the case where the one-firm-investing regions do not overlap as shown in Figure 3a, and then we extend the discussion to the overlapped case as shown in Figure 3b.

PROPOSITION 5 (SUPPLIER'S CAPACITY TYPE PREFERENCE WHEN $\left.\underline{w}_{0}^{e}(w) \geq \bar{w}_{0}^{f}(w)\right)$.

i) When $0 \leq w_{0}<\underline{w}_{0}^{f}(w)$ or $w_{0} \geq \bar{w}_{0}^{e}(w)$, the supplier is indifferent between the exclusive and firstpriority capacity.

ii) When $\underline{w}_{0}^{f}(w) \leq w_{0}<\bar{w}_{0}^{e}(w)$, the supplier prefers the exclusive capacity.

The results are illustrated in Figure 5a. Proposition 5(i) shows that if both firms invest or neither firm invests, the supplier is indifferent between the two types. This follows the discussion after Proposition 4 that the first-priority capacity is de facto exclusive in both cases, as firms compete in the Cournot market and have the same capacity level.

Figure 5 The Supplier's Preference about the Capacity Types

(a) One-firm-investing regions do not overlap (when $\underline{w}_{0}^{e}(w) \geq \bar{w}_{0}^{f}(w)$ )

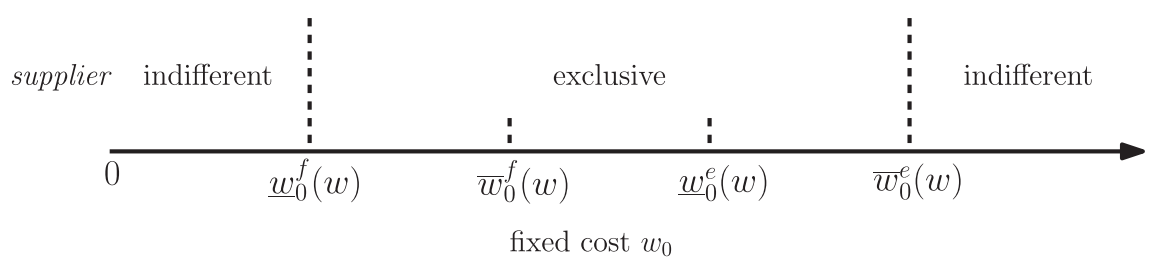

(b) One-firm-investing region overlaps (when $\underline{w}_{0}^{e}(w)<\bar{w}_{0}^{f}(w)$ )

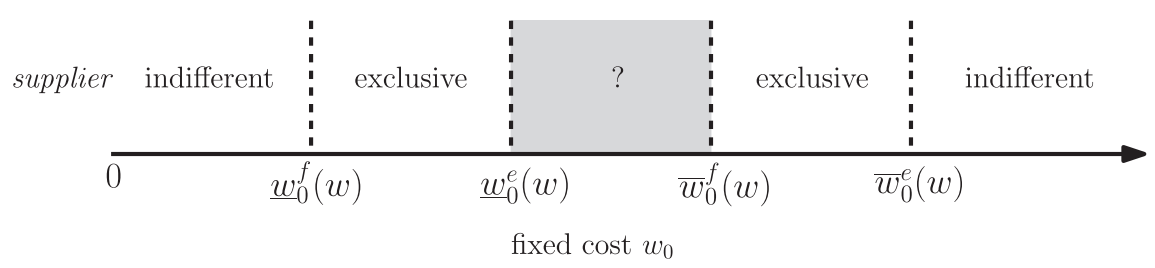


Proposition 5(ii) implies that in regions $\underline{w}_{0}^{f}(w) \leq w_{0}<\bar{w}_{0}^{e}(w)$, the supplier prefers the exclusive capacity to the first-priority capacity. In this region, the exclusive capacity results in strictly more firms investing. In the region where $\underline{w}_{0}^{f}(w) \leq w_{0}<\bar{w}_{0}^{f}(w)$, both firms invest under the exclusive contract and one firm invests under the firstpriority contract. Under the exclusive contract, both firms invest in the same capacity level in the supplier, and therefore either both firms will use up the invested capacity or both of them will have some leftover. That is, the supplier's capacity is utilized efficiently despite the exclusive claims. In addition, the total capacity invested by both firms with the exclusive capacity is higher than the total capacity invested by the one investing firm with the first-priority capacity. Therefore, the supplier is able to earn a higher profit with exclusive capacity and prefers the exclusive capacity to the first-priority capacity. In the region where $\bar{w}_{0}^{f}(w) \leq w_{0}<\underline{w}_{0}^{e}(w)$, neither firm invests under the first-priority contract and both firms invest under the exclusive contract, so the supplier is able to extract more profit from leveraging the additional invested capacity and it also prefers the exclusive capacity. Following a similar logic, in the region where $\underline{w}_{0}^{e}(w) \leq w_{0}<\bar{w}_{0}^{e}(w)$, neither firm invests under the first-priority contract and one firm invests under the exclusive contract, the supplier also prefers the exclusive capacity. These results are also shown in Figure 5 a.

We next consider the case when the one-firminvesting regions overlap $\left(\underline{w}_{0}^{f}(w) \leq w_{0}<\underline{w}_{0}^{e}(w)\right)$. Similar to the discussions on buying firms' preference, most of the results in Proposition 2 hold. However, we note that the supplier's preference is not trivial when the fixed cost $w_{0}$ is between $\underline{w}_{0}^{e}(w)$ and $\bar{w}_{0}^{f}(w)$. In this case, only one firm invests under both contracts, and the supplier gains more capacity investment with the exclusive capacity but loses the flexibility in using it. Intuitively, if the realized yield is small, the supplier may benefit from the over-investment with exclusive capacity. If the yield is moderately high, the supplier may benefit from the flexibility in utilizing the first-priority capacity. If the yield is high, the supplier is indifferent between the two capacity types as there is enough capacity to produce with either type. Thus, depending on which of the two effects dominates, the supplier's preference may change. Its preference depends on the parameters such as the distribution of the yield and the variable cost to invest in the capacity. The supplier's ex post profit is illustrated in Figure 6a. To further explore the supplier's preference between the two capacity types in this case, we conduct a numerical study below.

In Figure 7, we present a numerical example showing how the difference in the supplier's profit between exclusive and first-priority contracts changes in the variable capacity cost $w$, and the distribution of the yield $\xi$ when only one firm invests in the supplier. The first key observation is that the benefit from overinvestment in the exclusive capacity tends to dominate the benefit from the flexibility in the first-priority capacity, that is, $V_{s}^{e}\left(k_{1}^{e}, 0\right)-V_{s}^{f}\left(k_{1}^{f}, 0\right) \geq 0$. Let us take a closer look at one particular case of the ex post supplier's profit difference as shown in Figure 6b. It is clear that the region where the profit with exclusive capacity is greater than the profit with first-priority capacity, is greater than the other region, where the profit with exclusive capacity is smaller than the profit with first-priority capacity. This further confirms the conjecture that the over-investment benefit dominates the flexibility benefit. As the yield follows a uniform distribution between 0 and 1, we have that the ex ante expected profit with exclusive capacity is

Figure 6 The Supplier's ex post Subgame Perfect Equilibrium Profit when Only One Firm Invests (a); A Numerical Example of the ex post Profit Difference (b)
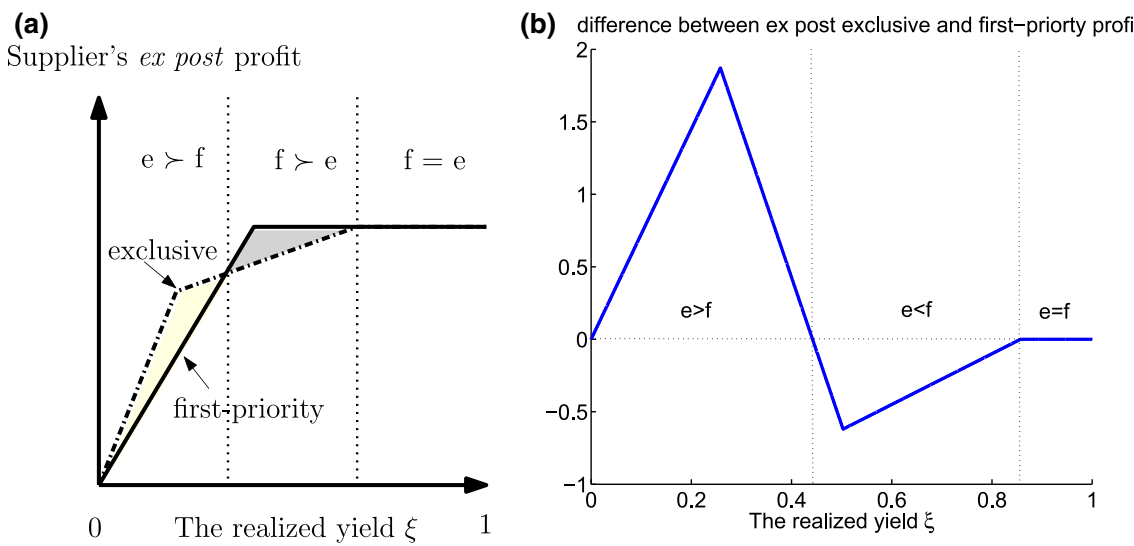

Parameters in $(b): a=10, b=1, c=1, w=0.1$, yield distribution $U[0,1]$, and supplier's base capacity $k_{0}=7$. 
Figure 7 The Supplier's Expected Profit Difference $V_{s}^{e}\left(\boldsymbol{k}_{1}^{e}, \mathbf{0}\right)-$ $V_{s}^{f}\left(k_{1}^{f}, \mathbf{0}\right)$

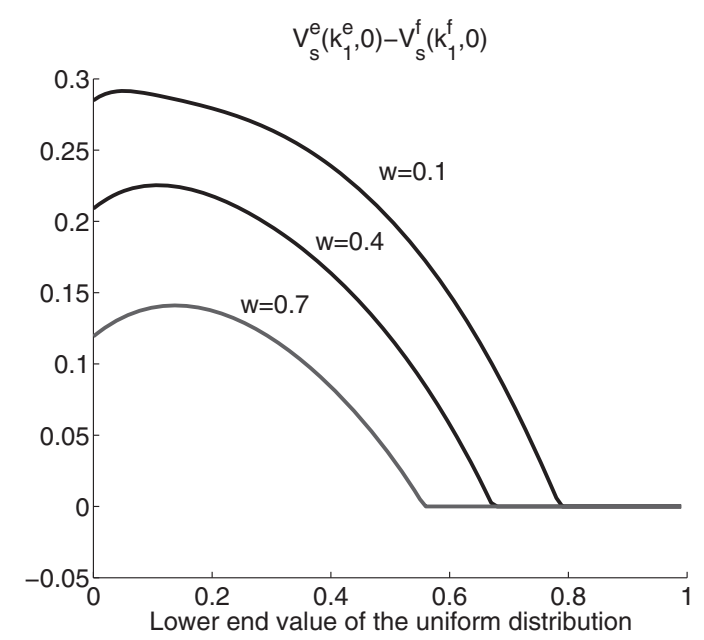

We notice that $V_{s}^{e}\left(k_{1}^{e}, 0\right)-V_{s}^{f}\left(k_{1}^{f}, 0\right)=V_{s}^{e}\left(0, k_{1}^{e}\right)-V_{s}^{f}\left(0, k_{1}^{\dagger}\right)$. Parameters: $a=10, b=1, c=1$, supplier's base capacity $k_{0}=7$ and the yield distribution $U[$ low, 1$]$ where the low value increases from 0 to 0.99 .

higher. Other cases are similar. While in this numerical example we illustrate that the benefit from the over-invested exclusive capacity often dominates the benefit from the flexibility in utilizing the first-priority capacity under the uniform yield distribution, the exact preference depends on the problem parameters and yield distribution in a general case.

Discussions on supply chain capacity. We have discussed different stakeholders' preference about the capacity type. Which capacity type will be eventually chosen is a complicated bargaining problem with the three stakeholders of the supply chain holding their own preferences. In the following discussions, we consider two extreme scenarios: the supplier decides the capacity type, or the investing firm decides the capacity type. The scenario in which the supplier chooses the capacity is appropriate when the supplier has a stronger bargaining power to dictate which type of capacity is to be installed at his site. We also consider the second scenario where the investing firm has a stronger bargaining power and determines the capacity type. As observed in the Foxconn-Sharp example discussed in the introduction, Foxconn as a buying firm effectively dictated that the capacity type be exclusive. We next discuss the two scenarios in detail.

- Supplier determines the capacity type. In this case, the supplier chooses the capacity type that will benefit him more, and the supplier is often better off under the exclusive capacity because doing so induces over-investment. The only exception to this happens when both the exclusive capacity and the first-priority capacity result in only one firm investing in equilibrium, that is, when $w_{0} \in\left[\underline{w}_{0}^{e}(w), \bar{w}_{0}^{\dagger}(w)\right]$. In this case, the supplier needs to consider the tradeoff between the larger but less flexible exclusive capacity and the smaller but more flexible first-priority capacity, as illustrated in Figure 6.

- Investing firm(s) decides the capacity type. When the investing firm decides the capacity type, a naive intuition would suggest that the investing firm should always claim exclusive use of its invested capacity. Although the intuition coincides with the equilibrium when the fixed cost is moderately high, that is, $w_{0} \in\left[\underline{w}_{0}^{e}(w), \bar{w}_{0}^{e}(w)\right]$, Figure 4 shows that this is not always the case. In particular, when the fixed cost is moderately low, that is, $w_{0} \in\left[\underline{w}_{0}^{f}(w), \bar{w}_{0}^{e}(w)\right]$, the investing firm is better off under the first-priority capacity. In this case, claiming exclusive use of the invested capacity triggers both firms to invest. In equilibrium one of the firms (say firm 1) invests under both the exclusive and first-priority scenarios, while the other firm (firm 2) invests in the exclusive capacity scenario but not in the first-priority scenario. From both firms' perspective, they are better off under the first-priority capacity. To see why, note that firm 1 is better off granting its competitor access to its invested capacity and keeping its leading position in the market. Firm 2 also prefers the first-priority capacity because it is forced to invest under the exclusive capacity and gets trapped in a worse situation. As a result, the investing firms (under the exclusive or the firstpriority capacity) prefer the first-priority capacity to the exclusive capacity.

Finally, we also acknowledge that the supply chain capacity type choice problem, which involves a multiparty negotiation, is still an open question. This is because, beyond these two scenarios, a number of factors (e.g., detailed sequence and rules of negotiation) can significantly influence which capacity type will emerge as an outcome of the three-party game. Although this is beyond the scope of this study, we believe that this can be an interesting future research question, following the recent emerging literature stream on bargaining in the supply chain setting, c.f., Lovejoy (2010) and Feng and Lu (2012).

\section{Conclusion}

We investigate two capacity contract structures that firms may engage in when investing in expansion of a shared supplier's capacity. We characterize the equilibrium outcomes, identify conditions about when and to what extent the spillover effect and prisoner's 
dilemma occur, and analyze the impact of the spillover effect on the equilibrium outcomes, and firms' and supplier's capacity type preferences.

Managerially, therefore, firms considering investing in suppliers who also supply their competitors must consider the consequences of their investment via the lens of a multi-player game, rather than myopically focusing on increased access to capacity. Placing restrictions on the supplier that are too tight may backfire in the form of competitors also jumping in with their own investments, which is reflected by the fact that more firms tend to invest and firms tend to over-invest with exclusive capacity in our model. We show that the spillover has both positive and negative effects on the investing firm. On the surface, allowing the spillover increases the end-market competition as more products are produced by both firms for a given capacity. On the other hand, allowing the non-investing firm to share the leftover capacity can actually disincentivize a need for investment, and, consequently, both firms may avoid being trapped in a prisoner's dilemma. Depending on two effects, the leading effect and the spillover effect for buying firms, different capacity types may be preferable. While the non-investing firm always prefers the first-priority capacity, the investing firm does not always want to shut off the other firm from accessing its invested capacity. By allowing access to the leftover, both firms could be better off. We also show that the supplier's preference is driven by the tradeoff between the over-investment in the exclusive capacity vs. the flexibility in utilizing the smaller first-priority capacity.

The results and insights of our study help us to understand the sequence of events that happened in the Foxconn-Sharp-Samsung case. Although there are many factors that affect Foxconn and Samsung's investment decisions, we highlight one particular factor in this case: Competing firms invest in a supplier to gain capacity. Despite its financial troubles, Sharp still maintains superior technology advantage in producing the LCD screens with the IGZO technology, and the factory in partnership with Hon Hai is the only one capable of producing the industry's largest sheets of glass panels (Osawa and Lee 2013). Therefore, it is critical for firms to secure supply from Sharp to maintain competitive advantage in the future. Driven by this motivation, Foxconn invested to secure $50 \%$ capacity of Sharp's Sakai factory, while Samsung also invested to prevent competitors to gain too much control over Sharp, and secure a steady supply of LCD panels. This competition for access to capacity is precisely what this paper considers, and this investment relationship is reflected in our model. As our analysis suggests, firms have to consider both direct and indirect consequences of their investment when they share a supplier with a competitor. Being too aggressive and claiming too much capacity may backfire as competitors may jump in with their own investment to prevent the firm from gaining a priority.

Our paper suggests several other directions for future research. One counterpart of our work could consider equilibrium outcomes if investments are used to reduce the uncertainty in the yield, rather than increase capacity. At a more general level, with the increasing trend of decentralized, networked, yet cooperative supply chains, the inter-dependency of the contractual relationship for one pair of agents with other agents could lead to unexpected outcomes. For example, what are the consequences of acquiring a supplier in such an environment? We believe there are several fruitful opportunities for research in this area.

\section{Acknowledgment}

The authors thank the Department Editor, the anonymous Senior Editor, and two anonymous referees for their comments and suggestions that have significantly improved this manuscript.

\section{References}

Aston, A. 2009. Wal-Mart: Making its suppliers go green. Bloomberg Businessweek. Available at http://www.businessweek.com/ magazine/content/09_21/b4132044814736.htm (accessed date October 31, 2011).

Babich, V. 2010. Independence of capacity ordering and financial subsidies to risky suppliers. Manuf. Serv. Oper. Manag. 12(4): 583-607.

Cachon, G. P., M. A. Lariviere. 1999. Capacity choice and allocation: Strategic behavior and supply chain performance. Manage. Sci. 45(8): 1091-1108.

Dignan, L. 2012. Supply chain wars: Hon Hai's Sharp investment helps Apple vs. Samsung. ZDNet. Available at http:// www.zdnet.com/blog/btl/supply-chain-wars-hon-hais-sharpinvestment-helps-apple-vs-samsung/72577 (accessed date May 20, 2012).

Feng, Q., L. X. Lu. 2012. The strategic perils of low cost outsourcing. Manage. Sci. 58(6): 1196-1210.

Handfield, R. B., D. R. Krause, T. V. Scannell, R. M. Monczka. 2000. Avoid the pitfalls in supplier development. Sloan Manage. Rev. 41(2): 37-49.

Haywood, K. 2009. GM helps axle maker avoid Chapter 11. The Wall Street Journal. Available at http://online.wsj.com/article/NA_WSJ_PUB:SB125322972929221255.html (accessed date October 31, 2011).

Iyer, A. V., L. B. Schwarz, S. A. Zenios. 2005. A principal-agent model for product specification and production. Manage. Sci. 51(1): 106-119.

Krause, D. R., R. B. Handfield, T. V. Scannell. 1998. An empirical investigation of supplier development: Reactive and strategic processes. J. Oper. Manag. 17(1): 39-58.

LaPedus, M. 2009. Intel invests in ASMI. EE Times. Available at http:/ / www.eetimes.com/ electronics-news/4082860/Intel-investsin-ASMI (accessed date October 31, 2011). 
Li, C. 2013. Sourcing for supplier effort and competition: Design of the supply base and pricing mechanism. Manage. Sci. 59(6): 1389-1406.

Li, C., L. G. Debo. 2009. Strategic dynamic sourcing from competing suppliers with transferable capacity investment. Nav. Res. Log. 56(6): 540-562.

Li, L., I. Duenyas, S. M. R. Iravani. 2011. Capacity option transfer rights: Do they benefit suppliers? Working paper, Northwestern University, Evanston, IL, and University of Michigan, Ann Arbor, MI.

Lovejoy, W. S. 2010. Bargaining chains. Manage. Sci. 56(12): 2282 2301.

Osawa, J., M.-J. Lee. 2013. Samsung to invest $\$ 110$ million in Sharp. The Wall Street Journal. Available at http://online.wsj.com/article/ SB10001424127887323628804578343912771185952. html (accessed date March 6, 2013).

Plambeck, E. L., T. A. Taylor. 2005. Sell the plant? The impact of contract manufacturing on innovation, capacity, and profitability. Manage. Sci. 51(1): 133-150.

Qi, A., H.-S. Ahn, A. Sinha. 2013. To share or not to share? Capacity investments in shared suppliers. Working paper, The University of Texas at Dallas, Richardson, TX, and University of Michigan, Ann Arbor, MI.

Sprumont, Y. 1991. The division problem with single-peaked preferences: A characterization of the uniform allocation rule. Econometrica 59(2): 509-519.

Ülkü, S., L. B. Toktay, E. Yücesan. 2005. The impact of outsourced manufacturing on timing of entry in uncertain markets. Prod. Oper. Manag. 14(3): 301-314.
Ülkü, S., L. B. Toktay, E. Yücesan. 2007. Risk ownership in contract manufacturing. Manuf. Serv. Oper. Manag. 9(3): 225-241.

Van Mieghem, J. A. 2003. Capacity management, investment, and hedging: Review and recent developments. Manuf. Serv. Oper. Manag. 5(4): 269-302.

Wadecki, A. A., V. Babich, O. Q. Wu. 2012. Manufacturers' competition and subsidies to suppliers. H. Gurnani, A. Mehrotra, S. Ray, eds. Supply Chain Disruptions: Theory and Practice of Managing Risk. Springer-Verlag London Ltd, New York, 141-164.

Wang, Y., W. Gilland, B. Tomlin. 2010. Mitigating supply risk: Dual sourcing or process improvement? Manuf. Serv. Oper. Manag. 12(3): 489-510.

Wang, Y., Y. Xiao, N. Yang. 2014. Improving reliability of a shared supplier with competition and spillovers. Eur. J. Oper. Res. 236(2): 499-510.

Zhu, K., R. Q. Zhang, F. Tsung. 2007. Pushing quality improvement along supply chains. Manage. Sci. 53(3): 421-436.

\section{Supporting Information}

Additional Supporting Information may be found in the online version of this article:

Appendix S1: Exclusive Capacity Contract.

Appendix S2: First-Priority Capacity Contract

Appendix S3: Spillover Effect: Comparing Exclusive and First-Priority Capacity

Appendix S4: Discussions on Sequence of Events. 